\title{
Natural history of prenatal isolated muscular ventricular septal defects
}

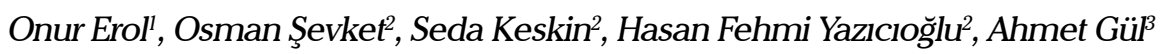 \\ 'Department of Obstetrics and Gynecology, Antalya Training and Research Hospital, Antalya, Turkey \\ ${ }^{2}$ Department of Obstetrics and Gynecology, Süleymaniye Maternity Research and Training Hospital Istanbul, Turkey \\ ${ }^{3}$ Department of Obstetrics and Gynecology, Istanbul Prenatal Center, Istanbul, Turkey
}

\section{Abstract}

Objective: To evaluate the natural history of isolated muscular ventricular septal (m-VSD) defects during gestation and up to 1 year postnatally, as well as the association with chromosomal anomalies.

Material and Methods: Between August 2007 and July 2012, 76 fetuses with isolated m-VSDs represented the study population. The following variables were evaluated: site and size of the m-VSDs, presence of chromosomal anomalies, pregnancy outcome, and spontaneous closure rate from diagnosis up to 1 year postnatally.

Results: Of the 76 cases with m-VSD, 1 fetus died after birth and 31 cases were lost to follow-up after birth. Thus, a total of 44 fetuses reached their first year of postnatal life, and these cases were available for analysis. Three (6.8\%) of 44 defects closed spontaneously in utero, 33 ( $75 \%$ ) closed within 1 year, and $8(18.2 \%)$ remained patent. Overall, spontaneous closure occurred more frequently in the apical defects, but no significant difference was found for spontaneous closure between the mid-muscular and apical defects ( $p>0.05$ ). Also, 83.8\% (36 of 44 ) of defects $\leq 3 \mathrm{~mm}$ closed during gestation or the first year of life.

Conclusion: We infer that m-VSDs have a high spontaneous closure rate during the first year of life. Also, small m-VSDs frequently close spontaneously. (J Turk Ger Gynecol Assoc 2014; 15: 96-9)

Key words: Isolated, muscular ventricular septal defect, spontaneous closure

Received: 15 January, $2014 \quad$ Accepted: 11 March, 2014

\section{Introduction}

Ventricular septal defect (VSD) is a common congenital heart defect (CHD), which accounts for up to $40 \%$ of cardiac anomalies (1). The prevalence of VSD varies among studies due to differences in methods of diagnosis and age of participants. The recent increased prevalence in neonates is attributable to changes in diagnostic methods and screening modalities, such as frequent use of fetal echocardiography (2).

An isolated VSD is defined as a defect in the interventricular septum without other sonographic abnormalities, but these defects are also found in association with other structural cardiac defects and complex malformations, such as transposition of the great arteries, congenitally corrected transposition, aortic coarctation or interruption, tetralogy of Fallot, and univentricular atrioventricular connection. Therefore, a detailed echocardiographic examination is warranted upon VSD detection.

The prevalence and natural history of prenatally isolated muscular VSDs (m-VSDs) have not been extensively reported. Little information is known regarding the rate of spontaneous closure during the pre- and postnatal period. The aim of this study was to evaluate the natural history and outcome of prenatally detected isolated $\mathrm{m}$-VSDs during gestation and the first year of life.

\section{Material and Methods}

A historical cohort study was performed on the results of fetal echocardiography conducted between August 2007 and July 2012 at İstanbul Prenatal Centre and Süleymaniye Maternity Hospital. Patients were referred for a routine second trimester anomaly scan and fetal echocardiography. All cases with a VSD as a component of complex CHDs, non-cardiac malformation, and known chromosomal abnormalities were excluded. The local ethics committee approved the study protocol.

Ultrasound scans were performed with the Voluson 730 system (GE Healthcare, Milwaukee, WI, USA) using either a 2-7 $\mathrm{MHz}$ or $4-8 \mathrm{MHz}$ transabdominal transducer. The left and right ventricular outflow tracts, major arteries, four-chamber view, three-vessel view, and basal short-axis view were evaluated using gray-scale echocardiography. Color Doppler imaging in at least 2 different planes was used to assess the interventricular septum and bidirectional flow across the defect 


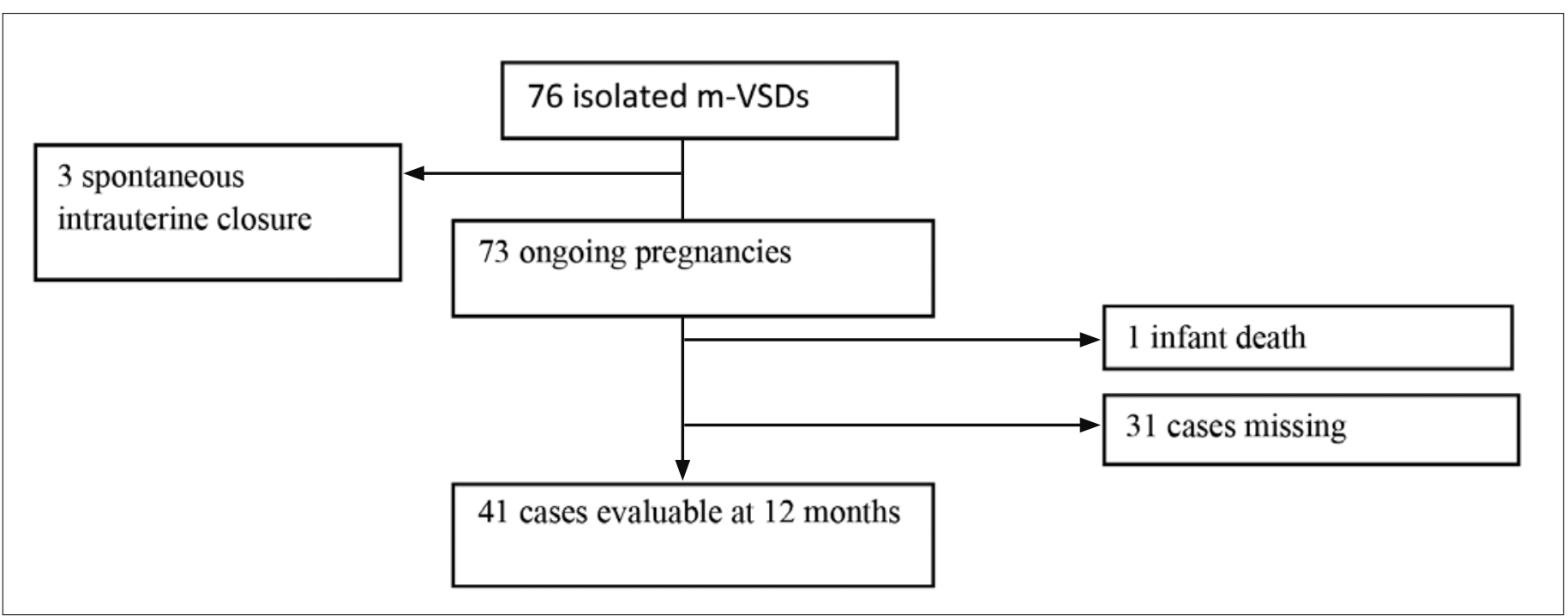

Figure 1. Cohort of the study

while perpendicular as possible to the ultrasound beam. Color velocity was reduced to a low Nyquist limit to capture lowspeed jets, since fetal right and left heart pressures are similar. Shunting across the septum was confirmed by pulsed-wave Doppler study.

Monthly follow-up antenatal visits were scheduled to evaluate the defect throughout gestation. As shown in Figure 1, 1 neonate from the original cohort of 76 isolated m-VSDs died 54 days after delivery due to carotid artery stenosis and cardiac failure. Thirty-one cases were lost to follow-up after birth. Thus, in the remaining 44 cases with isolated $\mathrm{m}$-VSD, complete follow-up during the first year of life was available for analysis.

The following data were retrieved from a computerized database: indication for fetal echocardiography, gestational age at diagnosis, site and size of defect, presence of chromosomal anomalies, intrauterine closure, pregnancy outcome, and neonatal follow-up until 12 months of life. The defect site was categorized as mid-muscular or apical. No anterior or posterior subtypes were detected. Fetal karyotyping following amniocentesis was performed in 18 (23\%) of 76 cases. Reliability of VSD diagnosis was confirmed by a postnatal pediatric cardiologist echocardiographic examination. All neonates were followed up until documented echocardiographic closure of the defect or 1 year of age.

Statistical analysis was performed with SPSS 17.1 for Windows (SPSS, Chicago, IL, USA). Fisher's exact test was used to evaluate inter-group differences. The level of statistical significance was set at $p$ equal to 0.05 .

\section{Results}

During the 5-year period, 534 cases of CHD were detected in 23,500 pregnancies referred for fetal echocardiographic examination. Overall, the CHD prevalence was $2.27 \%$ in this referralbased study group. There were 264 cases of VSD and 76 cases of isolated $\mathrm{m}-\mathrm{VSD}$, representing $49.43 \%$ and $14.23 \%$ of all CHDs, respectively.
The mean gestational age at diagnosis of isolated m-VSD was 23.1 (range 19-37) weeks. Indications for fetal echocardiography were fetal growth restriction in 4 cases $(5.2 \%)$, suspicion of CHD in 1 case (1.3\%), and a second trimester anomaly scan in 71 cases $(93.5 \%)$. Sixty-three (82.8\%) cases had a mid-muscular defect, and $13(17.2 \%)$ had an apical defect. The defect size was $\leq 3.0 \mathrm{~mm}$ in 74 cases (97.3\%), and $>3.0 \mathrm{~mm}$ in 2 cases (2.7\%). Karyotyping was performed in 18 (23.6\%) pregnancies, while in the remaining 58 cases, the karyotype was clinically assessed postnatally. No chromosomal anomalies were identified.

The mean gestational age and birth weight at delivery were 38.3 (range 31.0-41.0) weeks and 3197 (range 1000-5040) gr, respectively. As previously shown in Figure 1, 1 case of carotid artery stenosis was diagnosed in an infant who died at 54 days of age. Forty-four cases were investigated to determine the evolution of isolated $\mathrm{m}$-VSDs during intrauterine and postnatal life. The $\mathrm{m}$-VSD closure rates are presented in Table 1 . Three $(6.8 \%)$ of 44 defects closed spontaneously in utero, $33(75 \%)$ closed within 1 year, and $8(18.2 \%)$ remained patent. Three $(9.3 \%)$ of 32 mid-muscular defects closed spontaneously in utero, and 23 (71.8\%) closed within the first year. None of the apical defects closed in utero, and $10(83.3 \%)$ closed within the first year. While overall spontaneous closure occurred more frequently in the apical defects, no significant difference was found for spontaneous closure between the mid-muscular and apical defects ( $p>0.05$, OR 1.153, 95\% CI 0.198-6.679). In 8 neonates whose defects were not closed spontaneously during the first year of life, regular follow-up with an annual echocardiographic examination was planned.

The spontaneous closure rates according to the size of the defect are given in Table 2: $83.8 \%$ (36 of 44 ) of defects $\leq 3 \mathrm{~mm}$ closed during gestation or the first year of life, and only $16.2 \%$ ( 8 of 44 ) of $\mathrm{m}$-VSDs $\leq 3 \mathrm{~mm}$ remained patent during the followup period. We were unable to correlate the defect size with the spontaneous closure rate, because most $\mathrm{m}$-VSDs were small in size. Only 1 case with a diameter $>3 \mathrm{~mm}$ completed the followup, and this defect remained open at 12 months of life. 
Table 1. Closure of isolated $\mathbf{m}-$ VSDs by site

\begin{tabular}{|l|c|c|l|}
\hline $\begin{array}{l}\text { Site of the } \\
\text { m-VSD }\end{array}$ & $\begin{array}{c}\text { Closure in } \\
\text { Utero }\end{array}$ & $\begin{array}{c}\text { Closure During } \\
\text { the First } \\
\text { Year of Life }\end{array}$ & $\begin{array}{c}\text { No } \\
\text { Closure }\end{array}$ \\
\hline Mid-muscular & $3(9.3)$ & $23(71.8)$ & $6(18.9)$ \\
\hline Apical & - & $10(83.3)$ & $2(16.7)$ \\
\hline Total & $3(6.8)$ & $33(75)$ & $8(18.2)$ \\
\hline $\begin{array}{l}\text { m-VSD: muscular ventricular septal defect. Data presented as number } \\
\text { (percentage) }\end{array}$
\end{tabular}

Table 2. Closure of isolated m-VSDs by size of the defect

\begin{tabular}{|l|c|c|c|}
\hline $\begin{array}{l}\text { Size of the } \\
\text { m-VSD }\end{array}$ & $\begin{array}{c}\text { Closure in } \\
\text { Utero }\end{array}$ & $\begin{array}{c}\text { Closure During } \\
\text { the First } \\
\text { Year of Life }\end{array}$ & $\begin{array}{c}\text { No } \\
\text { Closure }\end{array}$ \\
\hline$\leq 3 \mathrm{~mm}$ & $3(6.9)$ & $33(76.7)$ & $7(16.4)$ \\
\hline$>3 \mathrm{~mm}$ & - & - & 1 \\
\hline Total & $3(6.8)$ & $33(75)$ & $8(18.2)$ \\
\hline $\begin{array}{l}\text { m-VSD: muscular ventricular septal defect. Data presented as number } \\
\text { (percentage) }\end{array}$
\end{tabular}

\section{Discussion}

This study is one of the largest cohorts evaluating the natural history of prenatally detected isolated m-VSDs. Midmuscular m-VSDs were approximately 5 -fold more prevalent than apical defects. Most of the m-VSDs (93.5\%) were diagnosed during the second trimester anomaly scan, highlighting the importance of targeted detailed ultrasound examinations to improve detection of CHDs.

In this study, spontaneous closure occurred prenatally and during the first year of life in $6.8 \%$ and $75 \%$ of the cases, respectively. Spontaneous closure is the most exciting aspect of the natural history of these defects. Resolution of an m-VSD could be part of antenatal development. Defects in the muscular septum close with the growth and hypertrophy of the surrounding muscular septum. Also, it has been proposed that small m-VSDs may be looked upon as a protracted process of closing multiple normally occurring channels in the inter-ventricular septum (3). The advent of color Doppler echocardiography has facilitated the evaluation of the perinatal course of these defects (4).

The size and site of the m-VSD are significant in its natural history. One study showed that velocity from right-to-left flow across the defect was negatively correlated with spontaneous closure rate for early closure of small $(\leq 3 \mathrm{~mm}) \mathrm{m}$-VSDs (5). Midmuscular VSDs frequently spontaneously close while also closing earlier than other types of muscular VSDs (6). In pediatric series in which the children were followed up from birth, spontaneous closure was seen in 81.8-84.8\% of m-VSDs during the first year of life. Closure occurred most frequently at the midmuscular location, while apical defects persisted more often $(7,8)$. Age at first echocardiographic examination and the length of the follow-up period may influence the spontaneous closure rate $(9,10)$. It has been demonstrated that $12.5-31 \%$ of m-VSDs can undergo spontaneous closure during fetal life
$(11,12)$. Results may vary due to the different classifications of VSDs. Our results show a lower rate of prenatal closure. Prenatal spontaneous closure occurred basically in the midmuscular VSD group, and no significant difference between the defect locations was found.

The rate of chromosomal anomalies associated with fetal isolated $\mathrm{m}$-VSDs is controversial. Two large series reported a rate of 28.6-38.2\% chromosomal anomalies associated with m-VSDs but included cases with extracardiac anomalies and associated known chromosomal anomalies $(12,13)$. Another study determined a $6.2 \%$ prevalence of aneuploidy associated with isolated VSD, but the study included a limited number of cases (11). No chromosomal anomalies were identified in our study, suggesting that isolated $\mathrm{m}$-VSD is a benign finding during pregnancy.

We acknowledge that our study also has several limitations. Firstly, the incidence of apical muscular VSDs is low, which limits the evaluation of the natural history of these defects. Secondly, $42.1 \%$ of cases were lost to follow-up during the postnatal period, limiting the conclusions. On the contrary, our results indicate that isolated $\mathrm{m}$-VSDs have no increased risk of chromosomal anomalies and have a high spontaneous closure rate during the first year of life. Also, small m-VSDs frequently close spontaneously. This information may be valuable to counsel parents at diagnosis.

Ethics Committee Approval: Ethics committee approval was received for this study from the local ethics committee.

Informed Consent: Written informed consent was obtained from patients who participated in this study.

Peer-review: Externally peer-reviewed.

Author contributions: Concept - A.G., H.F.Y.; Design - O.E.; Supervision - A.G., H.F.Y.; Resource - O.S., A.G.; Materials - A.G., H.F.Y.; Data Collection\&/or Processing - O.S., S.K., A.G., O.E.; Analysis\&/or Interpretation - O.E.; Literature Search - O.E.; Writing - O.E.; Critical Reviews - H.F.Y., A.G.

Conflict of Interest: No conflict of interest was declared by the authors.

Financial Disclosure: The authors declared that this study has received no financial support.

\section{References}

1. Hoffman JI. Incidence of congenital heart disease: I-postnatal incidence. Pediatr Cardiol 1995; 16: 103-13. [CrossRef]

2. Dolk H, Loane M, Garne E; European Surveillance of Congenital Anomalies (EUROCAT) Working Group. Congenital heart defects in Europe: prevalence and perinatal mortality, 2000 to 2005 . Circulation 2011; 123: 841-9. [CrossRef]

3. Meberg A, Otterstad JE, Frøland G, Lindberg H, Sørland SJ. Outcome of congenital heart defects - a population based study. Acta Paediatr 2000; 89: 1344-51. [CrossRef]

4. Cagh F, Basbug M, Ozgun MT, Oner G, Narin N, Akgun H, et al. Evaluation of the results of cases prenatally diagnosed as VSD. Erciyes Med J 2012; 34: 111-5. [CrossRef]

5. Jin Y, Wang A, Wang Y, Wang Y, Wang W, Hou X. Natural history of prenatal ventricular septal defects and their association with foetal echocardiographic features. Cardiol Young 2012; 22: 323-6. [CrossRef] 
6. Miyake T, Shinohara T, Inoue T, Marutani S, Takemura T. Spontaneous closure of muscular trabecular ventricular septal defect: comparison of defect positions. Acta Paediatr 2011; 100: 158-62. [CrossRef]

7. Du ZD, Roguin N, Wu XJ. Spontaneous closure of muscular ventricular septal defect identified by echocardiography in neonates. Cardiol Young 1998; 8: 500-5. [CrossRef]

8. Chang JK, Jien WY, Chen HL, Hsieh KS. Color Doppler echocardiographic study on the incidence and natural history of earlyinfancy muscular ventricular septal defect. Pediatr Neonatol 2011; 52: 256-60. [CrossRef]

9. Miyake T, Shinohara T, Nakamura Y. Spontaneous closure of ventricular septal defects followed up from $<3$ months of age. Pediatr Int 2004; 46: 135-40. [CrossRef]
10. Erdem S, Ozbarlas N, Kucukosmanoglu O, Poyrazoglu H, Salih OK. Long term follow-up of 799 children with isolated ventricular septal defects. Arc Turk Soc Cardiol 2012; 40: 22-5. [CrossRef]

11. Bahtiyar MO, Dulay AT, Weeks BP, Friedman AH, Copel JA. Prenatal course of isolated muscular ventricular septal defects diagnosed only by color Doppler sonography: single-institution experience. J Ultrasound Med 2008; 27: 715-20.

12. Axt-Fliedner R, Schwarze A, Smrcek J, Germer U, Krapp M, Gembruch U. Isolated ventricular septal defects detected by color Doppler imaging: evolution during fetal and first year of postnatal life. Ultrasound Obstet Gynecol 2006; 27: 266-73. [CrossRef]

13. Paladini D, Palmieri S, Lamberti A, Teodoro A, Martinelli P, Nappi C. Characterization and natural history of ventricular septal defects in the fetus. Ultrasound Obstet Gynecol 2000; 16: 118-22. [CrossRef] 